\title{
El ritmo de la agresión y el cementerio de la soledad. Acercamiento crítico a las formas del discurso en La Región más transparente de Carlos Fuentes
}

\section{The Rythm of Aggression and the Graveyard of Solitude. Critical approach to the forms of discourse in Carlos Fuentes Where the Air is Clear}

\section{Asher Gutkind ${ }^{1}$}

Universidad del Rosario, Escuela de Ciencias Humanas, GI Centro de estudios teológicos y de las religiones. Bogotá, Colombia.

ash.gut@gmail.com

\section{Resumen}

Se propone un estudio sobre las diversas formas de la escritura en la novela de Carlos Fuentes, La Región más transparente (1958). Las formas de la escritura se entienden como modalidades del discurso para construir mundos mentales, mitología propia, exclusiva de la novela misma, concepción de lo sagrado, del mito, de la moral, de lo político y un pensamiento de la misma creación literaria. Se propone mostrar cómo se estructura una escritura de la dominación, o ritmo de la agresión, particularmente en la forma de unos "círculos de lo corrupto": escritura sobre la dominación y escritura dominante, en cuya estructura se desenmascara cómo la corrupción del lenguaje tanto cotidiano, literario como político e histórico, dan paso a una crítica del lenguaje.

Palabras clave: Narrativa mexicana, escritura de la dominación, crítica del lenguaje.

\section{Abstract}

We try to study here the diverse forms of writing in the novel by Carlos Fuentes, Where the Air Is Clear (1958). The forms of writing are understood as modes of discourse in the way of building mental worlds, own mythology, conception of the sacred, myth, morals, the political and of the same literary creation. In this essay, we try to show how is structured a writing of domination, or the rhythm of aggression, here particularly a writing of the corrupt, in which structure is unmasked how the conception of ordinary, literary, political and historical speech and discourse, opens ways to a critique of language.

Keywords: Mexican Narrative, Narrative of Domination, Critique of Language.

1 Este texto es el resultado de una investigación en el marco de una Maîtrise en literatura hispanoamericana y estudios hispánicos e hispanoamericanos en la Universidad de Paris - Este - Marne-la-Vallée, en septiembre de 2001. 
¡Paradoja, metáfora, imagen, a qué peligros conducís!

Carlos Fuentes

\section{Introducción}

La Región más transparente (1958) es el segundo escrito publicado de Carlos Fuentes. Revelador de un joven escritor mexicano que la crítica mexicana no conocía, poco o menos, su libro desencadenó pasiones muy fuertes, tanto a favor como en oposición a lo que denunciaba como una novela "anti patriótica", "cosmopolita", como celebrando el nacimiento de una nueva corriente en la narrativa hispanoamericana. Lo que vamos a estudiar por qué es una novela revolucionaria, en qué medida es una obra que produce una crítica radical de la forma, lo que llamamos el ritmo de la agresión.

La agresión que leemos en la obra forma parte de un conjunto que llamamos también la crítica radical del lenguaje, que pensamos ser también una crítica radical del hombre.

Hemos observado tres formas fundamentales del lenguaje como esenciales en la obra de Fuentes.

La escritura de la corrupción nos parece ser en primer lugar uno de los programas de escritura de la novela. Integramos en nuestro estudio esta escritura de la corrupción de la palabra, esto es, del lenguaje, en los primeros análisis que hacemos de textos que nos han parecido tener los elementos como para hacer resaltar nuestra lectura.

La escritura del discurso en segundo lugar nos parece revelar un aspecto de la escritura fuentesina bastante importante. Ello se integra con el análisis de su quiebra y de la escritura de un mito, esto es, de la escritura de la crítica fundamental del lenguaje.

La escritura del mito está compuesta, en tercer lugar, de una escritura de lo sagrado, de una palabra sagrada que se destaca radical y violentamente de cualquier forma de coerción social o de lenguaje que no sea el que está reivindicado por la obra de Carlos Fuentes.

Hemos preferido a una exposición sintética y que estuviera por lo tanto alejada del texto, exponer estos tres niveles de la palabra, en consecuencia del lenguaje, con series de análisis del mismo texto que esperamos que cumplan con la claridad de lo que quisimos demostrar. La aridez del texto, el hermetismo a veces y la voluntaria falta de marco lineal para el lector de la novela, son elementos que no están para facilitar su estudio, y por lo tanto todavía menos su explicación. Los análisis no están, en nuestro estudio, apartados de las grandes líneas de fuerza de nuestra lectura que son la escritura irracional de la paradoja, que se ancla en una herencia literaria para mejor quebrarla y crear su otro nivel de visibilidad que es su mitología exclusiva de la novela de Fuentes, concebida por el autor como siendo la palabra sagrada. Expondremos en particular aquí una escena que podría pasar desapercibida en La región más transparente, que narra el entierro de la madre, Rosenda, de uno de los protagonistas de la novela, Rodrigo Pola. 
Él es un escritor fracasado que no se ha podido liberar de ciertas cadenas psicológicas y sociales, habiéndose quedado siempre al lado de su madre recién difunta. Se podría haber estudiado a este personaje (y a la novela) como figura de espejos, entre varios niveles de figuras semejantes de escritores, todas reenviando al mismo autor y a un ideal humano al que se hace referencia a lo largo de la obra. Sin embargo, hemos preferido enfatizar la distancia crítica que las voces narrativas imponen sobre los personajes mismos (sobre sí mismos como sobre los demás), mediante deformaciones y recreaciones de las personalidades. Una de las figuras más trabajadas por Carlos Fuentes, es la componente metafórica, mediante un paso por lo real, para que, luego de múltiples andares circulares, se desemboque sobre lo mítico, inventado por la novela, y por lo tanto, exclusive de ella, y que tiene el valor de revelaciones de lo sagrado.

\section{El cementerio de la soledad}

La novela de Carlos Fuentes tiene momentos, instantes de luz, como se puede notar en la escritura que analizamos en la última parte del estudio que proponemos, lo que leemos de Mercedes por ejemplo. Pero hay un nivel de lo oscuro por lo oscuro a lo que se ataca la escritura del autor Carlos Fuentes. Queremos decir que su intento literario más violento es una búsqueda de la luz. Una búsqueda de la luz que la escritura paradójica, que la creación metafórica dan una justificación al título de la novela: $L a$ región más transparente. Lo que vamos a tratar de demostrar es que esa luz, ese amor, esa transparencia que es uno de los anhelos más fuertes de la obra, no se aparta jamás de la escritura de la mugre, de la escritura de la muerte.

El pasaje del que nos proponemos dar un análisis no es más que un logro inverosímil de agresión, de la escritura de la muerte. A través del entierro de un personaje de madre, de madre solitaria, encerrada en su "maternidad", que como vamos a leer no es más que una declinación mórbida de un instinto de muerte, de una devoración por los sentimientos, por el círculo infernal de la devoración y de la auto-devoración, se ejerce la escritura de la agresión.

Este pasaje consta de dos niveles de narración: el primero es la voz de la narración y de cierta descripción en la que ambas pronto se apartan de su trayectoria como para crear otro nivel, interior, algo parecido a un monólogo que ya no es más un monólogo sino una espectacular forma que permite al autor amplificar el tono de una crítica radical de México, su estructura y de cierta tendencia hacia lo mortífero.

Se está haciendo una analogía entre la ciudad de México, la muerte y el personaje por lo tanto alegorizado. Una lógica de la agresión se manifiesta, pero de la agresión que crea un impulso fuertísimo para crear un espacio del amor.

El texto que nos proponemos estudiar es el siguiente: de la página 360 desde "Uno de los niños no corría ni pedía dinero" hasta la página 361 "salió del cementerio empapado". 
La dinámica que nos proponemos destacar es la siguiente: El diálogo; Los pensamientos de Ixca: la carcajada del demonio; Hasta el entierro final, la saña del narrador provoca asco y choque: una conmoción física y moral al lector.

El diálogo se compone de un intercambio entre Ixca Cienfuegos y el niño Jorge Morales. Lo que podemos notar en primer lugar es la diversidad muy grande de los estilos de Carlos Fuentes. Se trata de un intercambio que tiene mucho que ver con el realismo: describe la pobreza de los niños de México "no corría ni pedía perdón", sigue una descripción bastante precisa del niño y de su condición miserable "los pies desnudos" en el "lodo" (La región más transparente 360)

También podemos notar que se trata de un diálogo familiar "chamaco", "se sacan unos fierros" (361), que capta la vida de las márgenes miserables del México que iba creciendo, y del que hoy día ya se puede afirmar que igualó la pesadilla que sentía Carlos Fuentes en cuanto a la alcantarilla que anticipó que iba a llegar a ser aquella ciudad de México D.F.

Pero en seguida podemos notar una incursión de otro nivel de literatura: "Con las manos hacía disimuladamente cruces" que introduce un ambiente de miedo y de amenaza. El lodo, el cementerio, la presencia de la muerte, y de repente "No dejaba de hacer cruces y murmurar mientras miraba el agua turbia" (361) que introduce, por la intranquilidad del niño frente a la situación y sobre todo frente a Ixca Cienfuegos, un ambiente angustioso y fantástico de la novela gótica romántica de los ingleses del siglo diez y nueve.

Podemos también admirar el cinismo que ejerce Ixca Cienfuegos. Claro está que se hace un juego con Ixca Cienfuegos, juego con el personaje de demonio, pero también con un cierto aspecto bastante lúdico: se puede preguntar si no podría dar la noticia él mismo y no comprarle al niño. Obvio es que Carlos Fuentes juega con la situación para componer a la vez un pedazo de gótico, y para reírse del gótico haciendo un trozo bastante absurdo.

La última frase del pasaje denota la descarga del comienzo del pasaje que nos interesa en particular y lleva aliteraciones fuertes "carro arrancó" (361): aliteraciones muy sonoras y vivas que anuncian un impulso otro, el que sigue, sin duda.

Podemos notar también la alianza de los demonios entre Ixca y Teódula "LA madre" (361). Desde ese punto de vista, que reanuda con lo gótico, podemos notar la presencia de lo mitológico azteca, lo que abre otro nivel de lectura más que el gótico. Podemos admirar la variedad y la riqueza de los estilos acarreados por la pluma de Carlos Fuentes. Claro está que ahí Fuentes se burla de la mitología azteca, pues sin sangre alguna, sin sacrificio, ni plumas o carne comida, está relatado el rito azteca del sacrificio humano.

Por otra parte podemos señalar que sólo los guardianes demonios todavía tienen interés por esa madre que se murió, cuando el hijo ni está enterado; y que cuando se 
entera del hecho, ni logra, incluso esforzándose, sacarse una lágrima², “Una lágrima, siquiera una" se dice Rodrigo Pola (371, cursiva en el original). En efecto, sólo los guardianes de ella, de Rosenda, se preocupan de su muerte. Soledad entre soledades ni se quiere apercibir la sombra...

Se puede notar que toda la execrable mediocridad, la espantosa suciedad moral y vital del hombre de poco orgullo como lo diría Nietzsche, o de orgullo que no está bien situado, se concentra en el personaje de Rosenda Pola. En resumen, acarrea todas las carencias que puedan encontrarse en México. Es una mujer vacía, una falla. Un fracaso. Anti ejemplo de mujer.

Del pasaje que nos preocupa en especial, desde "Ixca pensó" (174), los pensamientos de Ixca Cienfuegos acerca del cadáver de Rosenda Pola, podemos afirmar que se trata de una analogía entre Rosenda y la ciudad de México. Llamaremos el pasaje la carcajada del demonio-demonio Ixca / demonio Fuentes. México está pintado como un cementerio, y desde luego se trata de una alegorización, claustro de muertos vivos.

Rosenda se presenta como una alegoría de éste, de la anti sexualidad, de la sexualidad mórbida y estéril, fracasada. Rosenda estación mediocre y detestable de la corrupción mexicana, de la escritura de la muerte.

Desde "Ixca pensó" se trata de un monólogo interior que no revela su nombre. El narrador ha desaparecido. La descripción deja lugar a la metáfora. En efecto, la narración va cada vez más hacia una metaforización de la ciudad como símbolo de muerte. Y hacia una pintura apocalíptica de un muerto vivo, de una vida sin más vida que la norma social y el claustro de adentro, que alarga en la muerte sin ruptura, pintura cínica por excelencia, el anti ejemplo de Rosenda que nunca vivió (lo que se opone absolutamente con el "nunca la recompensaría por no haber vivido" (513) de Mercedes Zamacona en su instante de revelación). Claro está que Rosenda no es más que una anti revelación, que un fracaso ante todo lo que compone la vida. Anti ejemplo totalmente negativo de Rosenda, que ya no tiene el nombre sino para oponerse a lo que simboliza, o hacer la inversión de los valores románticos. Rosenda es la que no se alza, no se aparenta a una rosa, como su nombre pudiera indicar, ni mucho menos.

Desde el episodio del álbum de Familia, página 174, "Rosenda se puso de pie con gran esfuerzo (sic) [...] dejaba que la saliva le escurriera sin control hasta el pecho" (174) (sin comentarios de más crueldad) al de su confesión sin eco durante su agonía, hasta su entierro, que es la risa ácida del desastre, Carlos Fuentes nos crea un personaje digno de la "oh! Faz de mi derrota, derrota mía" (185) desarticulado por el propio Ixca Cienfuegos. De la misma forma, el desenfreno crítico en contra de Rosenda está en completa analogía con el desenfreno crítico en contra de la ciudad de México.

2 Rodrigo Pola da toda la medida del amor que llevaba por su madre, que siendo extremamente presente ni le produce una lágrima. También se trata de otro juego de Carlos Fuentes que juega con la figura del macho mexicano, que no debe abrirse, que no debe sacar ningún sentimiento de debilidad, esto es, de sufrimiento, siquiera de amor (cf. Paz, Octavio. El laberinto de la soledad (1951). 
La conmoción violenta que provoca sobre el lector, a fortiori sobre un lector mexicano, es extrema.

Quizá, que yo sepa, L.F. Céline ${ }^{3}$ ya haya sido tan extremo en el negro de alcantarilla (la expresión es de Roland Barthes y la palabra en el texto). Quizá en las novelas de M. Blanchot se pueda hallar algo parecido, pero, sin duda, es enorme.

Interesémonos de más cerca en los "pensamientos" de Ixca.

Toda su vida, Rosenda fue un cadáver viviente: su muerte no es más que el alargamiento de su vida: un desastre: "el cadáver...semejaba el fruto" "envuelto en su mortaja" (174).

Produce aquí el Ixca / Fuentes una ironía mórbida: el fin de su vida, que era el fin de la sexualidad, la "gestación", "semejaba el fruto" (Ibíd.). Aquí la comparación es devastadora para el personaje. La sobrecarga semántica no se hace esperar, lo que no deja de producir un choque frontal con la escritura de México. Se está elaborando un desenfreno crítico hacia esa figura que se vuelve Rosenda de Muerte: Rosenda "siempre había soñado" "ese fruto" (Ibíd.), de ahora, es decir la gestación mortífera. Es decir también: no vivió, sino que soñó su vida. Pero no como Gérard de Nerval, cuyos libros lleva consigo Manuel Zamacona / Carlos Fuentes, que afirmaba "Le rêve est une seconde vie" (“Aurélia” 359) ${ }^{4}$, sino como un muerto vivo.

La gestación de Rosenda, en segundo lugar, no es más que la ilustración de lo que Carlos Fuentes aborrece: el fracaso, a fortiori, la sexualidad fracasada y escasa: además es una pequeña burguesa.

Así que la gestación de Rosenda no es más que gestación de la muerte.

Hay una verdadera labor de zapa que se está produciendo: el triángulo edipiano: madre-padre-hijo "fruto... de un padre y un hijo" (174) produce una ironía ácida, es de irrisión más cruel. El esquema freudiano es así, grosso modo: el hijo mata al padre para hacer el amor a la madre que desea. Ahora bien, la "gestación de padre e hijo" "se cumplía ahora" (Ibíd.), es decir en la muerte de la madre: es decir que no se cumplió nada sino que Rosenda fue un excepcional cadáver en el cual se estalla el esquema edipiano que resulta absurdo.

3 Para citar una frase "bonita" de aquel nihilista y genial escritor, cuyo colorido sin embargo indica aquella presencia de la muerte: "C'est effrayant ce qu’on en a des choses et des gens qui ne bougent plus dans son passé. Les vivants qu'on égare dans les cryptes du temps dorment si bien avec les morts qu'une même ombre les confond déjà" (Voyage au bout de la nuit 169) o también: "Les êtres vont d'une comédie vers une autre. Entre-temps la pièce n’est pas montée, ils n’en discernent pas encore les contours, leur rôle propice, alors ils restent là, les bras ballants, devant lévénement, les instincts repliés comme un parapluie, branlochants d'incohérence, réduits à eux-mêmes, c’est-à-dire à rien. Vaches sans train” (260), y todavía mucho más explícita, aquella famosa frase hacia el final del Viaje: “ [...] un homme [...] ce n'est rien après tout que de la pourriture en suspens..." (426).

4 Se trata en el caso de Nerval de una comparación muy interesante pues Manuel reivindica la imaginación como fuerza de vida. Además, en el caso de Rosenda, se trata de exactamente lo contrario del sueño desenfrenado y librador de espíritu de Nerval, mientras que en el caso del personaje de Rosenda ya no se trata más que de un sueño más bien pesadilla inverosímil de esterilidad. Se trata más bien de una resignación ante la nada. Por supuesto con otro imaginario muy diferente, pero al revés de Nerval, como Stéphane Mallarmé, celebra el vacío en una filosofía de la nada: "Ce lac dur oublié que hante sous le givre/Le transparent glacier des vols qui n’ont pas fui!" ("este lago duro olvidado que debajo de la cencellada dura se aparece/el transparente glaciar de los vuelos que no huyeron"). 
Además, el producto de su "gestación” no es más que un cadáver, no es más que su propio cadáver, lo que no deja de producir una visión horrífica. Y encima de todo en "La gestación que ella añoraba repetir" (174). Otra vez, podemos señalar la labor de zapa. Se trata de repetir, que pueden ser también los ciclos cósmicos de la vida, lo que no deja de producir una destrucción muy violenta de aquella mitología de la madre cósmica.

Pero también puede ser el cumplimiento en la muerte que es el ideal cristiano, por lo menos del cristianismo medieval, tanto como el sacrificio a los dioses aztecas (el Sol). En efecto, no hay cumplimiento alguno, sino que no hay nada, no hay nada sino la nada. Se trata de la nada "chata, gris, y teñida" (Ibíd.) sin ningún lirismo romanticista.

Se puede afirmar que una visión extremamente audaz y corrosiva se manifiesta.

La sexualidad cadavérica de Rosenda no es más que la sexualidad cadavérica de la ciudad de México. México está pintado como una ciudad cadavérica y su habitante, el capitalino del D.F., ya no es más que vegetal mortífero. Se trata de una alegorización de México D.F. tras Rosenda.

Primero es una "ciudad chata, gris, teñida" (Ibíd.): impone ya una visión de descomposición. El efecto producido achica la ciudad chata para imponerla, dominarla, englobar y descomponer bajo los ojos de Ixca Cienfuegos corrosivos y sin ninguna complacencia. "Veía correr a su lado la ciudad” (Ibíd.): podemos señalar aquí la presencia fuertísima de Balzac: visión balzaciana de Rastignac: "Rastignac... vit Paris couché le long des deux rives de la Seine...", sólo que Rastignac diciendo "A nous deux, maintenant" (Le Perè Goriot 342-43) a la ciudad, es un ejemplo social, o por lo menos un emblema de lo que pudo analizar Balzac como el auge del capitalismo francés, mientras que Ixca es un personaje anti realista, primero, y más o menos diabólico, y no forma parte de la ambición burguesa espectacular de Rastignac que tan bien había captado Balzac, como emblema también de su escritura de conquista "Le génie procède de deux manières : ou il prend son bien comme Napoléon et Molière aussitôt qu'il le voit, ou il attend qu'on le vienne chercher quand il s'est patiemment révélé" (La Vieille Fille 29), sino de una ambición mitológica destructora aniquiladora.

Ixca, entre otras cosas, es una recreación del dios azteca del Norte, Tezcatlipoca, de la destrucción, espejo de humo, y por lo tanto podemos notar que Ixca hace surgir la componente oscura, insana, mortífera del mundo azteca.

Su madre Teódula le pide un sacrificio para cumplir el rito, lo que revela el lado mortífero de la mitología azteca como la concebía Carlos Fuentes y fue puesta aquí bajo su pluma crítica.

Ahora bien, Rosenda podría representar ese sacrificio, pero, no tiene, ni mucho menos, la muerte de Rosenda el carácter del sacrificio ritual (porque no se puede decir que Ixca la mató, quizá la dejó morir).

"Chata, gris, teñida", "lluvia que no se resignaba a confundirse con el suelo", "permanecía en el lodo y el regurgitar de alcantarilla" (174): nos encontramos en esa visión de descomposición frente a lo que nos proponen los pensamientos de Ixca 
Cienfuegos (se trata del "stream of consciousness" versión Céline, lo que es sin duda una proeza agresiva): la descomposición, (cerca de lo que Barthes llamaba de Céline "du tout à légoût"), es la metáfora elemental del cadáver de Rosenda que prepara la metáfora casi hiperbólica macabra, de la ciudad de México. Con "una vasta placenta" que resume todos los elementos negativos de la vida de Rosenda, México D.F. alegorizado allí por Rosenda, la ultra mediocre mujer.

La palabra "fusilamientos" hace referencia a la guerra de la revolución mexicana, en su aspecto más estéril y negativo, sobre todo que sigue estrechamente "amor exigido" que podría ser el paradigma de la corrupción, oponiéndose al amor procreador de Hortensia y Mercedes.

Ello puede simbolizar la relación de Rosenda con su falso héroe que era Gervasio Pola, extrapolado en el mexicano medio, del erotismo pequeño burgués que odia Carlos Fuentes. La "indiferencia personal" denota claramente la mediocridad de vida de cada uno en México. Sin duda podemos señalar que no se trata de una crítica racional, además de ser una sobrecarga semántica. El discurso mediocre, el amor mediocre, el sexo mediocre, se estallan en la nada en los oídos de Ixca.

El autor produce una yuxtaposición de elementos muy diversos y diferentes que tienen que ver con lo mexicano, pero sobre todo con la rabia que puede tener Carlos Fuentes en cuanto a lo que no se hace de bien, de bueno o de grande.

Fuentes se muestra muy audaz, por no decir más: la "vasta placenta” en que se transforma la ciudad, nutre a cuatro millones de cadáveres. La audacia ya consigue su paroxismo más alto. La ciudad sólo puede ser negativa. El efecto literario es muy impactante. De nuevo, podemos hablar de Céline, el malísimo genio.

En el útero mismo está la componente de muerte: Cioran tal vez se asustaría él mismo.

"Cuatro millones se alineaban... cada uno rígido... muro coronado de pólvora" (174): pocos ejemplos literarios han logrado producir tanto mortífero efecto...

La ciudad está vista como un cementerio: ya no es más del "laberinto de la soledad" de que se trata -"sin tocarse las manos" (Ibíd.)- sino del cementerio de la soledad.

De la misma manera, la anáfora "Cuatro millones" de la frase da el mismo efecto, pero produciendo un crescendo aun nihilista, "sin solución".

Y se expresa casi una condescendencia paródica para aquellos pobres mexicanos que en su "parto repetido con el ejercicio doloroso de la premura" paren sus días y sus noches como autómatas "sin solución" "sin memoria" y aun "sin posibilidad de resurrección” (Ibíd.); esto es, sin la redención a la que llama Manuel/Fuentes, y que encarna Robles al final de la parte segunda de la novela, al final de la novela de Federico Robles.

Pero allí encontramos la cumbre de la rabia de amor de Carlos Fuentes: la carcajada del demonio: parece decir a los capitalinos, lo que Carlos Fuentes fue, ustedes no tiene nada, no son más que cadáveres vivientes que se dan la mano a otros cadáveres, y no tienen, ni mucho menos, (lo que estaba presente en los intelectuales de la época en México) los mitos mexicanos para renacer como el Sol Huitzilopochtli. 
Hasta el entierro la hosquedad del texto provoca asco y choque: la conmoción física y moral de la obra se revela de manera flagrante.

Reanuda con la narración propiamente dicha las últimas líneas del texto que escogimos como ejemplo vivo de la escritura de la agresión de Carlos Fuentes.

Un panteísmo de descomposición y no de creación como en Uruapan con Mercedes, se está manifestando: "vereda fangosa, la lluvia" (174). Pero es una descripción muy brutal, un realismo al que vuelve el autor, como en el principio del texto que estudiamos.

La entera frase que empieza por "Las gotas de lluvia le escurrían..." (Ibíd.) posee nueve sonidos en $[\mathrm{G}] \mathrm{o}[\mathrm{K}]$ : ¿no serán los golpes del infierno, como los nueve jirones del infierno, de Vulcano, de la nada, en la cabeza del lector - serán los nueve círculos y conmociones del dantesco Carlos Fuentes?

En todo caso, la insistencia en sonoridades fuertes y rugosas, se hace gracias a un trabajo poético cuidadoso e intenso de escritura.

Reanuda con la focalización interna - "la lluvia le escurría" y "las huellas" (Ibíd.)que forma parte del enfoque sobre el personaje de Ixca Cienfuegos. Las huellas se borran: esto confirma la idea de la inconsistencia de Rosenda.

Último rasgo de cinismo macabro: "la fosa llena de agua" (Ibíd.)- podemos ver a Rosenda en un naufragio, que vuelve a la tierra, como haciendo un elemento de burla, lúdico: podemos leerlo como el último elemento de ese texto en la carcajada del demonio Ixca / Fuentes.

El enigmático perdón de Ixca Cienfuegos nos deja perplejo. Claro está que se trata del perdón a su madre por no haber cumplido con el sacrificio ritual. Pero el efecto cómico de la palabra en ese contexto de furia nos da a pensar en otra cosa. ¿Por qué diablos Ixca nos deja pensativos en tener que pedir perdón? Y si no hay nadie. Será una ironía más. Una ironía hacia el lector: nos pide perdón a nosotros lectores como si supiera que estuvo muy lejos en la rabia. O será que justamente Ixca no sabe decir perdón y lo dice cuando ya no sirve y no se escucha y ya no es un perdón sino un murmullo del agua fangosa.

La vuelta al mundo real se hace de manera tan violenta como el tono del texto lo mantuvo. "Salió del cementerio empapado" (Ibíd.) además de ser un elemento un tanto cómico por ser tan realista y descriptivo, como una broma, como si dijera todo aquello sólo para eso. Vuelta al mundo real: ¿a los muertos vivos?, o existen también algunos que viven?

Vuelta a Rodrigo. El hijo que aprende la muerte de su madre, pues Teódula acaba de salir "volando", otra ironía fuentesina, y escribe. El hijo escribe cuando su madre murió. Y sobre qué. Sobre México y lo que le guste. No construyendo tragedias como William Faulkner, quien escribía una tragedia cuando se moría un prójimo, empezaba una novela para vencer la muerte. Rodrigo Pola escribe ideas sobre México que les parece revelar su condición dramática, a él en particular.

Es un pasaje clave de la novela que acabamos de estudiar. Es algo revelador de lo que podemos ahora llamar la escritura de la agresión. En la región de alcantarilla se 
sitúa el entierro de Rosenda que alegoriza el entierro de una ciudad por su guardián. Añadamos que esa "muerte sin fin" negativa y horrífica, desencadena en la novela la creación de totalidad de destrucción: estilos, temas, espíritu de síntesis, espíritu de análisis como un Balzac escribiendo como un poeta con Joyce, Proust, Freud, la Revolución mexicana y Céline que pasaron por aquí. Con una rabia llena de amor. No olvidar el cementerio de la soledad. En una lógica de agresión, por todos los medios que intenta crear, Carlos Fuentes, hacia todo lo que odia o ama en México, logra crearnos un impacto fantástico.

Pero entonces, cuando muera la soledad en el cementerio que Carlos Fuentes le dibujó con una furia digna de Goya, otra relación será tal vez posible.

\section{Conclusiones}

Repetida dos veces, la exclamación de Manuel Zamacona "Paradoja, metáfora, imagen, a qué peligros conducís!” $(182,195)$, resume a nuestro parecer la escritura de la novela. Basada sobre un anclaje primero y estacional de lo real, la escritura de la agresión que caracteriza la obra, abre perspectivas de lo metafórico y de una mitología que es exclusiva del autor e incluso de esta obra. Abre perspectivas de una abertura más amplia que es la del amor, de una mística del amor muy particular de esta obra del novelista mexicano.

Es una revelación del ser, y desde ahí una revelación del mundo, y sobre todo de los demás seres. Es "humanismo místico". La crítica de la forma, radical en la obra, se acompaña de una crítica de la lectura, radical para cada persona que se emplea en hacer el esfuerzo, y al final, el placer de leer la novela: "Leer una novela es un acto amatorio que nos enseña a mejor amar".

\section{Referencias}

Balzac, Honoré de. La Comédie Humaine. Paris: Gallimard, 1981. Medio impreso.

---. La Vieille Fille. Houssiaux, 1874. Medio impreso.

---. "Le Père Goriot" Euvres complètes de H. de Balzac. Paris: Calmann-Lévy, 1910. Wikisource.

Barthes, Roland. Le Degré zéro de l'écriture suivi de Nouveaux essais critiques. Paris: Éditions du Seuil, 1953. Medio impreso.

Blanchot, Maurice. L'Espace littéraire. Paris: Gallimard, 1955. Medio impreso

---. Thomas l'obscur. París:Tel-Gallimard, 2005. Medio Impreso.

Bonnefoy, Yves. L'improbable et autres essais. Paris: Folio-essais, 1992. Medio Impreso. ---. Poèmes. París: Gallimard, 1982. Medio impreso.

Céline, Louis-Ferdinand. Voyage au bout de la nuit. Paris: Gallimard, Folio n 28, 1972. 
Cioran, Emil. CEuvres. París: Gallimard-Bibliothèque de la Pléiade, 2011. Medio impreso Fuentes, Carlos. La Región más transparente. Madrid: Cátedra, 1982. Medio Impreso. ---. Geografía de la novela. Buenos Aires: Fondo de Cultura Económica,1993. Medio Impreso.

Genette, Gérard. Figures I. Paris: Le Seuil, 1966. Medio Impreso.

---. Figures III. Paris: Le Seuil, 1972. Medio Impreso.

---. Palimpsestes. Paris: Le Seuil, 1982. Medio Impreso.

Nerval, Gérard de. "Aurélia”. Euvres. Paris, Gallimard, 1960. Medio Impreso.

Paz, Octavio. El laberinto de la soledad. Postdata. Vuelta a El laberinto de la soledad. México: Fondo de Cultura Económica, 2000. Medio Impreso.

Proust, Marcel. À la recherche du temps perdu. Paris: Gallimard, 1987-1989. Medio Impreso.

Sarraute, Nathalie. Euvres complètes. Paris: Gallimard, 1996. Medio Impreso.

Recibido: 22 octubre 2013 Aceptado: 07 noviembre 2014 